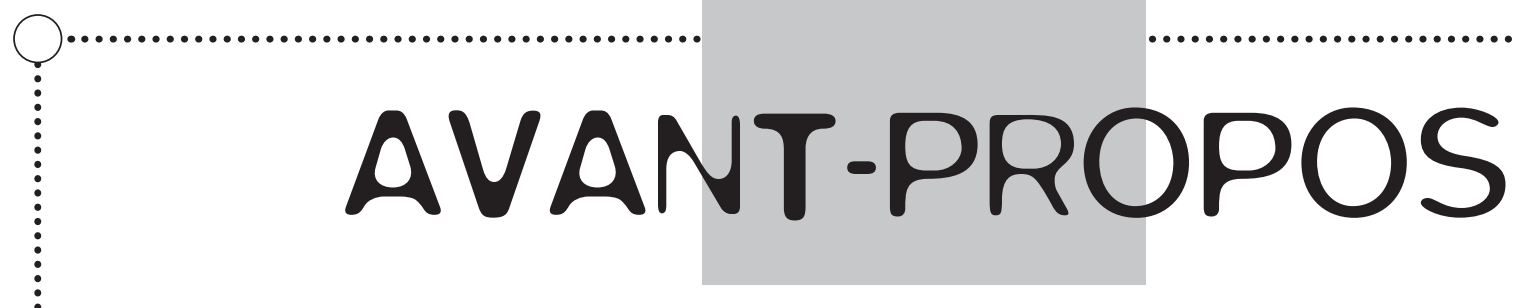

${ }^{1}$ Psychiatre, Psychanalyste (SPP) Médecin directeur de La Velotte, Centre Psychothérapique de La Velotte, 8, chemin de la Vosselle, 25000

Besançon, France. pasama@wanadoo.fr

\title{
Le travail en équipe et la clinique de la psychose
}

\section{The teamwork and the clinics of psychosis}

\author{
Pascale de SAINTE MARIE ${ }^{1}$
}

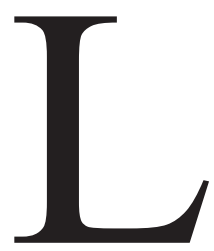

es textes rassemblés dans ce dossier s'enracinent dans le travail en équipe auprès des patients accueillis au Centre Psychothérapique de La Velotte pour des souffrances psychiques graves. Nous souhaitons souligner l'importance du travail collectif basé sur la coopération du patient, de ses parents et de l'équipe médicosoignante. En référence au concept d'ambiguité tel que Paul-Claude Racamier l'a différencié de l'ambivalence, nous montrerons notre intérêt pour le travail sur les bordures, entre le dedans et le dehors, entre l'individuel et le collectif, entre la responsabilité et la sécurité, entre la continuité et l'imprévu, entre le psychique et le pragmatique, qui permet de séparer et de relier, de différencier pour faire ensemble et de favoriser des prises de positions contrastées au sein de l'équipe soignante. Cela nous permet d'offrir aux patients une enveloppe vivante et transformante qu'ils peuvent utiliser pour mettre au travail leur problématique interne et relier entre elles des parties clivées d'eux-mêmes projetées sur les soignants. Nous en témoignerons dans quatre textes, les deux premiers restituant les questions institutionnelles avec Marcel Sassolas, fondateur des équipes de "Santé Mentale et Communauté » lyonnaises, d'abord puis Gilbert Diatkine. Les deux textes suivants, proposés par Alain Gibeault puis Vincent Rebière, nous introduisent au cœur du parcours clinique des patients, le premier évoquant le travail en psychodrame, le second mettant en évidence la complémentarité féconde du suivi psychiatrique et psychanalytique. - 

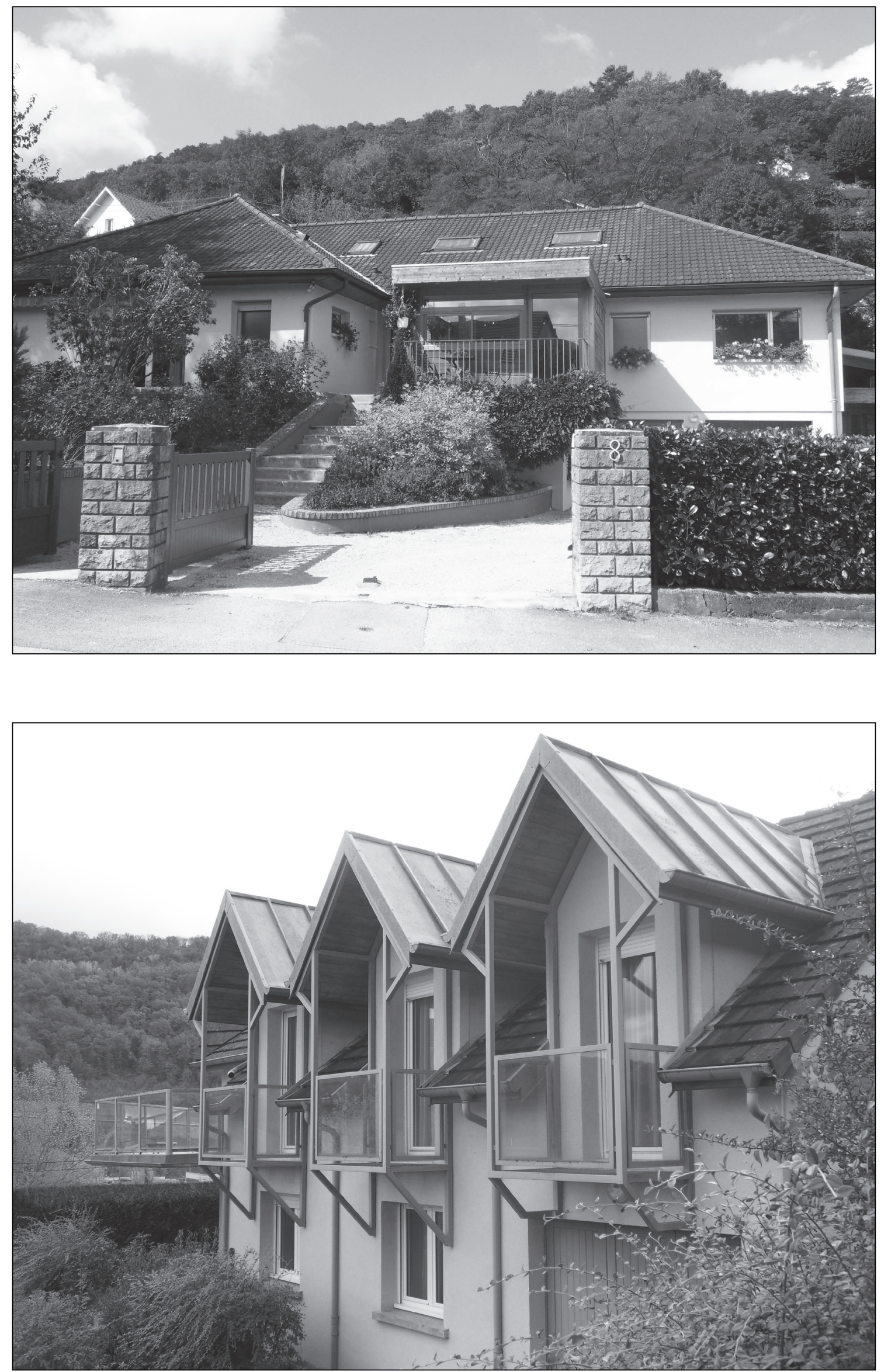